\title{
A Longitudinal Study Examining Self-Regulation Practices in Older Drivers with and without Suspected Mild Cognitive Impairment
}

\author{
Ying Ru Feng' \\ Lynn Meuleners' \\ Mark Stevenson ${ }^{2,3}$ \\ Jane Heyworth (iD ${ }^{4}$ \\ Kevin Murray ${ }^{4}$ \\ Michelle Fraser' \\ Sean Maher ${ }^{5}$ \\ 'Western Australian Centre for Road \\ Safety Research, School of Population and \\ Global Health, The University of Western \\ Australia, Perth, WA, Australia; \\ ${ }^{2}$ Transport, Health and Urban Design \\ Research Lab, Melbourne School of \\ Design, University of Melbourne, \\ Melbourne, VIC, Australia; ${ }^{3}$ Melbourne \\ School of Population and Global Health, \\ University of Melbourne, Melbourne, \\ VIC, Australia; ${ }^{4}$ School of Population and \\ Global Health, The University of Western \\ Australia, Crawley, WA, 6009, Australia; \\ ${ }^{5}$ Department of Rehabilitation and Aged \\ Care, Sir Charles Gairdner Hospital, \\ Perth, WA, Australia
}

Correspondence: Lynn Meuleners Western Australian Centre for Road Safety Research, School of Population and Global Health, The University of Western Australia (M43I), 35 Stirling Hwy, Perth,

WA, 6009, Australia

Tel +6I 864887375

Email lynn.meuleners@uwa.edu.au
Purpose: Mild cognitive impairment can impact driving performance and self-regulation practices. However, there is little evidence on how cognitive impairment may impact these self-regulation practices over a period of time. Therefore, the aim of this study was to examine changes in the number and type of situations in which older drivers with and without suspected mild cognitive impairment (MCI) self-regulate their driving over a oneyear period, after accounting for relevant confounders.

Participants and Methods: A longitudinal cohort study involving older drivers (65+ years) from metropolitan Western Australia was interviewed by a telephone interview at baseline and one-year follow-up. The Telephone Cognitive Screen (T-CogS) was also administered to determine changes in their cognitive status. The outcome of interest was the number and type of situations older drivers self-regulated their driving.

Results: A total of 670 drivers were interviewed at baseline (suspected MCI: $n=227$; no cognitive impairment: $n=443$ ) and one-year follow-up (suspected MCI: $n=251$; no cognitive impairment: $\mathrm{n}=419$ ), which provided 1340 observations. Drivers with suspected MCI increased the number of driving situations in which they self-regulated by $13 \%$ over a period of one-year compared with drivers without cognitive impairment $(\mathrm{IRR}=1.13,95 \% \mathrm{CI}=1.02-1.27, \mathrm{p}=0.025)$. Specifically, drivers with suspected MCI had $60 \%$ increased odds of self-regulating when "making turns across oncoming traffic" compared with drivers without cognitive impairment (unadjusted OR $=1.60$, $95 \% \mathrm{CI}=1.02-2.53, \mathrm{p}=0.041)$. Other significant factors included being female $(\mathrm{IRR}=1.87,95 \%=$ $1.52-2.32, \mathrm{p}=0.001)$, aged $75+$ years $(\mathrm{IRR}=1.33,95 \% \mathrm{CI}=1.10-1.60, \mathrm{p}=0.003)$, higher number of comorbidities $(1-3$ comorbidities: $\mathrm{IRR}=1.26,95 \% \mathrm{CI}=1.01-1.58, \mathrm{p}=0.040 ; 4+$ comorbidities: $\mathrm{IRR}=1.39,95 \% \mathrm{CI}=1.08-1.78, \mathrm{p}=0.011)$, "decreased driving confidence" $(\mathrm{IRR}=1.32,95 \% \mathrm{CI}=$ $1.10-1.58$, p-value $=0.003)$ and "preference of having someone else drive" $($ IRR $=1.38,95 \% \mathrm{CI}=$ $1.12-1.70, \mathrm{p}=0.003)$. Having one or more traffic infringements was also associated with a decrease in the number of self-regulated driving situations ( $I R R=0.80,95 \% \mathrm{CI}=0.67-0.95, \mathrm{p}=0.011)$.

Conclusion: Over a one-year period, drivers with suspected MCI increased the number of situations in which they self-regulated their driving compared with drivers without cognitive impairment, particularly when "making turns across oncoming traffic". Future studies should examine whether this increase in the types and number of self-regulated driving situations is enough to compensate for declines in cognition.

Keywords: longitudinal, cognitive decline, driving behaviour, driving restriction, driving patterns

\section{Introduction}

Driving is a complex activity, which requires the coordination of visual, physical and cognitive skills by an individual. ${ }^{1}$ In older drivers, the natural aging process can 
cause a decline in one, if not all three of these skills. Consequently, any changes in these abilities is likely to impact on their driving performance and behaviour. ${ }^{2,3}$

Driver self-regulation is a strategy used by older drivers to modify or restrict their driving to compensate for any decline in functional abilities. ${ }^{4}$ It can minimize their driving in hazardous situations while maintaining their independence and mobility. ${ }^{4}$ Self-awareness and perception are key components in driver self-regulation practices ${ }^{5}$; however for drivers with cognitive conditions such as dementia or mild cognitive impairment (MCI), deficits in cognitive ability may lead to inadequate selfregulation practices. ${ }^{6}$

Mild cognitive impairment (MCI) is a transitional cognitive state between normal cognitive aging and dementia, which affects approximately $20 \%$ of older adults aged $65+$ years. ${ }^{7,8}$ Although cognitive decline may not be severe enough to impact activities of daily living, more demanding tasks such as driving may present challenges. Previous studies found that drivers with MCI were more likely to perform worse in on-road driving assessments in regards to driving errors and driver safety, when compared with drivers without cognitive impairment. ${ }^{9-11}$ Driving simulator studies also found that drivers with MCI had a shorter mean time to collision (time to contact the preceding vehicle if car is moving under constant velocity), ${ }^{12}$ were less likely to comply with stop signs ${ }^{13}$ and had greater trouble maintaining a proper headway from the vehicle in front. ${ }^{14}$ Drivers with MCI were also found to restrict their overall driving exposure, ${ }^{15,16}$ as well as limiting their driving in certain situations including on high-density roads, ${ }^{17}$ in wet conditions ${ }^{18}$ and at night. ${ }^{18}$ While most studies have found that drivers with cognitive impairment are more likely to undertake self-regulation practices, some studies have found no difference in self-regulation practices between drivers with and without MCI. A study by Katsouri et al found that self-reported avoidance of certain driving situations, such as driving at night or when it was raining, was not significantly different between drivers with MCI and healthy controls. ${ }^{19}$ Similarly, a more recent study by Vardaki et al found that both drivers with and without MCI showed similar patterns and frequency in driving situations including driving at night, driving in the rain and driving over long distances. $^{20}$

Although there is significant research examining selfregulation patterns for drivers with $\mathrm{MCI}$ and without cognitive impairment, these were cross-sectional studies. ${ }^{17-20}$
However, examining changes in self-regulation practices can be particularly pertinent for older drivers with MCI due to the dynamic nature of the condition. One study which examined longitudinal changes in self-regulation practices in older drivers concluded that increases in selfregulation behaviour did not occur in conjunction with declines in functional abilities including vision and visual attention. ${ }^{21}$ An added complexity to examining changes in self-regulation practices is that while a diagnosis of MCI may increase the risk of developing dementia ( 4-6\% conversion per year in the community $)^{22}$ many older adults with MCI may transition back to normal cognition $(\sim 16 \%$ reversion per year $) .^{23}$

In Western Australia, there is no age requirement in which older drivers must cease driving and compulsory on-road driving assessments for older drivers aged 85+ years was stopped in $2013 .^{24}$ Therefore, it is important to monitor older drivers to assess how age-related conditions such as MCI may impact on their driving. The aim of this study was to examine changes in the number and type of situations in which older drivers with and without suspected MCI self-regulate their driving from baseline to a one-year follow-up assessment, after accounting for relevant confounders. It was hypothesized that there will be a difference between drivers with and without suspected MCI regarding changes in the type and number of situations drivers self-regulated between baseline and oneyear follow-up.

\section{Methods \\ Study Design}

A longitudinal study of older adults, aged $65+$ years, with and without suspected MCI, was undertaken over a oneyear period. This study is part of a prospective cohort study examining cognitive ability and driving. ${ }^{25-27}$

Ethics approval was obtained from the Human Research Ethics Committee at The University of Western Australia (RA/4/20/5126) and followed the Declaration of Helsinki. Before any information was collected from participants, informed consent was obtained. Participants were told that they could withdraw from the study at any time.

\section{Sample}

Potential older participants were identified from a customized Western Australian (WA) database of all older drivers in the Perth metropolitan area by interviewers 
from the Survey Research Centre (SRC) at Edith Cowan University. Recruitment of participants was limited to seven local government areas known to have a higher prevalence of people with cognitive impairment and dementia. ${ }^{28}$ Baseline recruitment of potential participants, sample size calculations and eligibility criteria were previously reported. ${ }^{27}$ Participants who were eligible at baseline and agreed to be contacted at the one-year follow-up were recruited by the SRC. Baseline data collection occurred between November 2018 and February 2019 and the one-year follow-up data collection occurred between November 2019 and December 2019. Participants were contacted between the hours of 9AM to 9PM, Monday to Friday. At follow-up, participants were called up to three times, before being classified as a nonrespondent.

\section{Data Collection}

Participants were administered the same questionnaire regarding socio-demographic and driving characteristics, including the Driving Habits Questionnaire (DHQ) and Telephone Cognitive Screen (T-CogS) at baseline and oneyear follow-up.

Socio-demographic characteristics including age, gender, marital status, education level, living arrangements, comorbidities (eg, heart disease, diabetes, arthritis, chronic kidney disease, hearing impairment, visual impairment, high blood pressure), prescription medication, driving characteristics (license restrictions, crashes and traffic infringements in the past year, changes in driving confidence and preference of transportation), cognitive status, self-regulation practices, attitudes towards driving cessation and community mobility and transportation options were collected. This questionnaire took approximately 25 minutes to complete.

\section{Telephone Cognitive Screen (T-CogS)}

The Telephone Cognitive Screen (T-CogS), ${ }^{29}$ which is a 26-point cognitive screening test that can be administered over the phone, was used to screen for suspected MCI. This test is an adaption of Folstein's Mini-Mental State Examination (MMSE). ${ }^{30}$ The T-CogS and MMSE are strongly correlated $(r=0.88)$ and have been validated in a cohort of patients with Alzheimer's disease. ${ }^{29}$ Participants who scored between 21 and 24 on the T-CogS were classified as having suspected MCI, while participants who scored 25 or 26 on the T-CogS had no cognitive impairment. ${ }^{29,31}$ It is acknowledged that the categorization of suspected MCI by the T-CogS does not infer clinically defined MCI as diagnosed by the Peterson/ Mayo criteria. ${ }^{32}$ The T-CogS takes approximately 5-10 minutes to complete.

Researchers administering the $\mathrm{T}-\mathrm{CogS}$ were blind to the cognitive score/status of participants at the baseline and the one-year follow-up interview to minimise information bias.

\section{Self-Regulation Status}

Participants were asked nine questions based on the Driving Habits Questionnaire (DHQ) ${ }^{33}$ about situations in which they self-regulated their driving. This questionnaire was previously validated on a Western Australian older driving population. ${ }^{34}$ Self-regulation status was determined by whether or not a participant had driven in any of the following driving situations in the past three months: "driving when it is raining", "driving alone", "parallel parking", "making turns across oncoming traffic", "driving on highways or freeways", "driving on heavy traffic roads", "driving in peak hour traffic", "driving at night" and "driving at night in the rain". For example, the participant was asked "During the past 3 months, have you driven when it is raining?" The participant response for each of the nine driving situations was a binary outcome (yes/no), which was used to assess changes in driver self-regulation for each situation over the one-year study period. Then, the total number of situations in which a participant self-regulated their driving was calculated by summing up the number of different situations, which could range from zero to nine, to be used in the multivariate analysis.

\section{Statistical Analysis}

Descriptive and inferential statistics were used to describe the socio-demographic characteristics and changes in driving characteristics over the one-year period. A paired $t$-test was used to examine changes in the number of driving situations over the one-year study period.

The outcome of interest was the number of driving situations in which older drivers self-regulated their driving. Nine separate univariate generalized estimating equation (GEE) logistic regression models were undertaken to assess the changes in self-regulation practices from baseline to the one-year follow-up in each of the nine driving situations for drivers with and without suspected MCI. No adjustment (Bonferroni correction) was made for multiple 
testing, and therefore p-values are suggestive of an association.

A multivariate generalized estimating equation (GEE) Poisson regression model was also undertaken to assess changes in the total number of situations a participant selfregulated their driving from baseline to the one-year followup after accounting for potential confounders, including cognitive status. Potential confounders included in the model were based on a systematic review by Wong et al which included gender, age, marital status, number of comorbidities, the number of crashes and traffic infringements in the previous year, changes in driving confidence, and preference of transport. ${ }^{35}$

Based on the review by Wong et al, separate interaction terms between time/gender $(\mathrm{p}=0.08)$, time/cognition $(\mathrm{p}=0.81), \quad$ time/age $\quad(\mathrm{p}=0.51 / \mathrm{p}=0.97) \quad$ and gender/age $(p=0.71 / p=0.98)$ were included in the model but were not significant and removed from the final model. However, the interaction term between gender/driving confidence was significant $(\mathrm{p}=0.01)$ and included in the final model.

All statistical analyses were carried out using SAS 9.4 (SAS Institute, NC, USA).

\section{Results}

At the one-year follow-up, 688 of the 973 participants who completed the baseline questionnaire, were able to be recontacted and participated in the follow-up interview. However, nine participants were excluded as they had a T-CogS score of 20 or under, and a further nine participants had stopped driving. The remaining 670 participants were included in the final sample, which represented a response rate of $70.71 \%$. A total of 1340 observations were available for the data analysis.

There were no statistically significant differences in gender $(p=0.444)$, age $(p=0.641)$ and self-regulation status $(p=0.135)$ between respondents and non-respondents for the follow-up interview.

\section{Socio-Demographic Characteristics}

The socio-demographic characteristics for drivers who completed both assessments are summarised in Table 1. A significantly larger proportion of male drivers had suspected MCI (54.19\%) compared with females $(40.86 \%)$ $(p=0.001)$. Drivers with suspected MCI were also significantly older $(\mathrm{p}=0.001)$, with the majority aged $75+$ years (43.61\%), compared with drivers without cognitive impairment, the majority of whom were aged 70-74 years $(38.37 \%)$.
There were no significant differences between drivers with suspected MCI and without cognitive impairment for marital status $(p=0.828)$, highest education achieved $(p=0.251)$, living arrangement $(p=0.929)$, number of comorbidities $\quad(p=0.106)$, prescription medication $(p=0.097)$, license restriction $(p=0.979)$, number of crashes in the past year (suspected MCI: mean $=0.05$, range $=0-2$; no cognitive impairment: mean $=0.06$, range $=0-2$; $\mathrm{p}=0.568$ ) and number of traffic infringements in the past year (suspected MCI: mean $=0.13$, range $=0-2$; no cognitive impairment: mean $=0.14$, range $=0-3 ; \mathrm{p}=0.877$ ).

\section{Changes in Cognitive Status from Baseline to One-Year Follow-Up}

Based on the result of the T-CogS questionnaire, at baseline 227 of the 670 participants $(33.88 \%)$ were classified with suspected MCI, which increased to 251 participants $(37.46 \%)$ at the one-year follow-up representing $10.57 \%$ increase in the number of participants with suspected MCI.

Cognitive status in 412 of the 670 participants $(61.49 \%)$ did not change from baseline assessment to oneyear follow-up. However, 141 participants (21.04\%) progressed from having no cognitive impairment to suspected MCI at the one-year follow-up and 117 participants $(17.46 \%)$ reverted from having suspected MCI at the baseline to no cognitive impairment at the one-year follow-up. This conversion rate of $17 \%$ from suspected MCI to no cognitive impairment is consistent with previous research. $^{23}$

\section{Changes in Driving Situations from Baseline to One-Year Follow-Up}

At baseline, there was no significant difference in the number of situations drivers with suspected MCI (mean=1.34, $\mathrm{SD}=1.61$ ) and drivers without cognitive impairment (mean=1.11, $\mathrm{SD}=1.33$ ) self-regulated their driving $(\mathrm{p}=0.064)$. Similarly at the one-year follow-up, there was no significant difference in the number of situations drivers with suspected MCI (mean=1.24, $\mathrm{SD}=1.47$ ) and drivers without cognitive impairment (mean=1.07, $\mathrm{SD}=1.36)$ self-regulated their driving $(\mathrm{p}=0.139)$.

When assessing the change from baseline to the oneyear follow-up, there was also no significant difference in the number of situations drivers with suspected MCI and without cognitive impairment self-regulated their driving $(t=1.18, d f=669, \mathrm{p}=0.238)$. 
Table I Socio-Demographic Characteristics for Older Drivers with and without Suspected $\mathrm{MCl}$ at Baseline $(n=670)$

\begin{tabular}{|c|c|c|c|}
\hline & No Cognitive Impairment (at Baseline) & Suspected $\mathrm{MCl}$ (at Baseline) & p-value \\
\hline & $(n=443)$ & $(n=227)$ & \\
\hline & n (\%) & n (\%) & \\
\hline Gender & & & $0.001 *$ \\
\hline Male & I8I (40.86) & $123(54.19)$ & \\
\hline Female & $262(59.14)$ & $104(45.81)$ & \\
\hline Age Group & & & $0.001 *$ \\
\hline $65-69$ years & $143(32.28)$ & $55(24.23)$ & \\
\hline 70-74 years & $170(38.37)$ & $73(32.16)$ & \\
\hline$\geq 75$ years & $130(29.35)$ & $99(43.61)$ & \\
\hline Marital Status ${ }^{\mathrm{a}}$ & & & 0.828 \\
\hline Married/De facto & $349(79.14)$ & $178(78.41)$ & \\
\hline Single/Separated/Divorced/Widowed & $92(20.86)$ & 49 (21.59) & \\
\hline Highest Education Achieved ${ }^{\mathrm{a}}$ & & & 0.251 \\
\hline Primary/Secondary & $169(38.15)$ & $97(42.73)$ & \\
\hline Higher Education & $274(61.85)$ & $130(57.27)$ & \\
\hline Living Arrangements ${ }^{a}$ & & & 0.929 \\
\hline Alone & $85(19.23)$ & $43(18.94)$ & \\
\hline Not Alone & $357(80.77)$ & $184(81.06)$ & \\
\hline Number of Comorbidities & & & 0.106 \\
\hline None & $48(10.84)$ & $28(12.33)$ & \\
\hline $\mathrm{I}-3$ & $290(65.46)$ & $130(57.27)$ & \\
\hline $4+$ & $105(23.7)$ & $69(30.4)$ & \\
\hline Prescription Medication & & & 0.097 \\
\hline No & $94(21.22)$ & $36(15.86)$ & \\
\hline Yes & 349 (78.78) & $191(84.14)$ & \\
\hline Crashes (in the past year) ${ }^{\mathrm{a}}$ & & & 0.568 \\
\hline None & $418(94.57)$ & 217 (95.59) & \\
\hline$\geq 1$ & $24(5.43)$ & $10(4.4 I)$ & \\
\hline Traffic Infringements (in the past year) ${ }^{\mathrm{a}}$ & & & 0.877 \\
\hline None & $386(87.13)$ & $197(87.56)$ & \\
\hline$\geq 1$ & $57(12.87)$ & $28(12.44)$ & \\
\hline License Restriction & & & 0.979 \\
\hline No & $390(88.04)$ & $200(88.11)$ & \\
\hline Yes & $53(11.96)$ & $27(11.89)$ & \\
\hline
\end{tabular}

Notes: aMissing information. $*_{p}<0.05$.

Abbreviation: $\mathrm{MCl}$, mild cognitive impairment.

At baseline, the three most frequent situations in which a participant self-regulated their driving was "driving at night in the rain" (suspected MCI: $\mathrm{n}=110,48.46 \%$; no cognitive impairment: $\mathrm{n}=192,43.34 \%$ ), "parallel parking" (suspected MCI: $\mathrm{n}=28,21.15 \%$; no cognitive impairment: $19.41 \%, \mathrm{n}=86$ ), followed by "driving when it is raining" (suspected MCI: $17.62 \%, \mathrm{n}=40$; no cognitive impairment: $16.70 \%, \mathrm{n}=74)$. At the one-year follow-up, a similar pattern was evident with the most frequently reported situations being "driving at night in the rain" (suspected MCI: $\mathrm{n}=107,42.63 \%$; no cognitive impairment: $\mathrm{n}=170$, 40.57\%), and "parallel parking" (suspected MCI: $n=48$,
$19.12 \%$; no cognitive impairment: $\mathrm{n}=79,18.85 \%$ ). However, the third most frequently self-regulated situation was different for drivers with suspected MCI and without cognitive impairment. For drivers with suspected MCI, it was "driving at night" $(\mathrm{n}=40,15.94 \%)$ and for drivers without cognitive impairment it was "driving during peak hour" $(\mathrm{n}=48,11.46 \%)$.

Table 2 summarizes the changes from baseline to the one-year follow-up for each of the nine specific driving situations for participants with and without suspected MCI. While the odds of self-regulation increased for all driving situations for those with suspected MCI, the only 
Table 2 GEE Logistic Regression Models Assessing Changes in Self-Regulation Practices for Each Driving Situation from Baseline to One-Year Follow-Up for Drivers with and without Suspected $\mathrm{MCl}(\mathrm{n}=670)$

\begin{tabular}{|c|c|c|c|c|c|}
\hline Driving Situation & & OR* & \multicolumn{2}{|c|}{$95 \% \mathrm{Cl}$} & p-value \\
\hline Driving when it is raining & $\begin{array}{l}\text { No cognitive impairment } \\
\text { Suspected } \mathrm{MCl}\end{array}$ & $\begin{array}{c}1 \\
1.08\end{array}$ & 0.76 & 1.53 & 0.670 \\
\hline Driving alone & $\begin{array}{l}\text { No cognitive impairment } \\
\text { Suspected } \mathrm{MCl}\end{array}$ & $\begin{array}{c}1 \\
1.15\end{array}$ & 0.38 & 3.55 & 0.803 \\
\hline Parallel parking & $\begin{array}{l}\text { No cognitive impairment } \\
\text { Suspected } \mathrm{MCl}\end{array}$ & $\begin{array}{c}1 \\
1.06\end{array}$ & 0.82 & 1.37 & 0.651 \\
\hline Making turns across oncoming traffic & $\begin{array}{l}\text { No cognitive impairment } \\
\text { Suspected } \mathrm{MCl}\end{array}$ & $\begin{array}{l}1 \\
1.60\end{array}$ & 1.02 & 2.53 & $0.04 I^{* *}$ \\
\hline Driving on highways or freeways & $\begin{array}{l}\text { No cognitive impairment } \\
\text { Suspected } \mathrm{MCl}\end{array}$ & $\begin{array}{c}1 \\
1.42\end{array}$ & 0.72 & 2.78 & 0.307 \\
\hline Driving on heavy traffic roads & $\begin{array}{l}\text { No cognitive impairment } \\
\text { Suspected } \mathrm{MCl}\end{array}$ & $\begin{array}{c}1 \\
1.58\end{array}$ & 0.95 & 2.62 & 0.077 \\
\hline Driving during peak hour & $\begin{array}{l}\text { No cognitive impairment } \\
\text { Suspected } \mathrm{MCl}\end{array}$ & $\begin{array}{c}1 \\
1.08\end{array}$ & 0.8 & 1.47 & 0.601 \\
\hline Driving at night & $\begin{array}{l}\text { No cognitive impairment } \\
\text { Suspected } \mathrm{MCl}\end{array}$ & $\begin{array}{c}1 \\
1.24\end{array}$ & 0.91 & 1.69 & 0.167 \\
\hline Driving at night in the rain & $\begin{array}{l}\text { No cognitive impairment } \\
\text { Suspected } \mathrm{MCl}\end{array}$ & $\begin{array}{c}1 \\
1.11\end{array}$ & 0.9 & 1.37 & 0.330 \\
\hline
\end{tabular}

Notes: *Univariate logistic odds ratio. $* * p<0.05$.

Abbreviations: $\mathrm{MCl}$, mild cognitive impairment; $\mathrm{Cl}$, confidence interval; OR, odds ratio.

significant finding was that drivers with suspected MCI had $60 \%$ increased odds of self-regulating when "making turns across oncoming traffic" compared to drivers without cognitive impairment (unadjusted $\mathrm{OR}=1.60,95 \%$ $\mathrm{CI}=1.02-2.53, \mathrm{p}=0.041)$.

Table 3 summarizes the results of the GEE Poisson regression model. The number of situations in which a driver with suspected MCI self-regulated their driving increased by $13 \%$ over one year compared with a driver without cognitive impairment ( $\mathrm{IRR}=1.13,95 \% \mathrm{CI}=1.02-$ $1.27, \mathrm{p}=0.025)$. Females increased the number of situations they self-regulated their driving by $87 \%$ compared with male drivers over the year $(I R R=1.87,95 \%=1.52-2.32, \mathrm{p}=0.001)$. As well, drivers aged 75+ years increased the number of situations they self-regulated their driving by $33 \%$ compared with drivers 65-69 years over the year (IRR $=1.33,95 \%$ $\mathrm{CI}=1.10-1.60, \mathrm{p}=0.003)$. For drivers with one to three comorbidities, the number of self-regulated driving situations increased by $26 \%(I R R=1.26,95 \% \mathrm{CI}=1.01-1.58, \mathrm{p}=0.040)$ and $39 \%(I R R=1.39,95 \% \mathrm{CI}=1.08-1.78, \mathrm{p}=0.011)$ for drivers with four or more comorbidities, compared with drivers with no comorbidities over the year. The number of self- regulated driving situations decreased by $20 \%$ over the year for those who received one or more traffic infringements compared with drivers who did not receive a traffic infringement (IRR $=0.80,95 \% \mathrm{CI}=0.67-0.95, \mathrm{p}=0.011)$. For drivers who reported a "decrease in driver confidence" the number of self-regulated driving situations increased by $32 \%$ compared with drivers who reported an "increase/no change in driver confidence" over the year (IRR $=1.32,95 \% \mathrm{CI}=1.10-1.58$, $\mathrm{p}$-value $=0.003$ ). For drivers who preferred "someone else driving", the number of self-regulated driving situations increased by $38 \%$ over the year compared with drivers who preferred to "drive themselves" (IRR $=1.38,95 \% \mathrm{CI}=1.12$ $1.70, \mathrm{p}=0.003$ ).

\section{Discussion}

The present study built on our previous research examining self-regulation practices in older drivers with and without $\mathrm{MCI},{ }^{27}$ by examining the changes in the number and type of situations a driver self-regulated their driving over a one-year period. The current study found that drivers with suspected MCI increased the number of driving situations they self-regulated in by $13 \%$ from baseline to the 
Table 3 GEE Poisson Regression Model Assessing Changes in the Number of Situations Drivers with and without Suspected $\mathrm{MCl}$ Self-Regulated Their Driving, Over One Year $(n=670)$

\begin{tabular}{|c|c|c|c|c|}
\hline \multirow{2}{*}{ Cognition } & \multirow[t]{2}{*}{ IRR } & \multicolumn{2}{|c|}{$95 \% \mathrm{Cl}$} & \multirow[t]{2}{*}{ p-value } \\
\hline & & & & \\
\hline No cognitive impairment* & 1 & & & \\
\hline Suspected $\mathrm{MCl}$ & 1.13 & 1.02 & 1.27 & $0.025 * *$ \\
\hline \multicolumn{5}{|l|}{ Time } \\
\hline Baseline* & 1 & & & \\
\hline Follow-up & 0.92 & 0.84 & 1.01 & 0.066 \\
\hline \multicolumn{5}{|l|}{ Gender } \\
\hline Male* & 1 & & & \\
\hline Female & 1.87 & 1.52 & 2.32 & $0.001 * *$ \\
\hline \multicolumn{5}{|l|}{ Age Group } \\
\hline $65-69$ years* & 1 & & & \\
\hline $70-74$ years & 0.98 & 0.83 & 1.15 & 0.812 \\
\hline $75+$ years & 1.33 & 1.10 & 1.60 & $0.003 * *$ \\
\hline \multicolumn{5}{|l|}{ Marital Status ${ }^{\mathrm{a}}$} \\
\hline Married/De facto* & 1 & & & \\
\hline Single/Separated/Divorced/ & 0.98 & 0.83 & 1.17 & 0.860 \\
\hline \multicolumn{5}{|l|}{ Widowed } \\
\hline \multicolumn{5}{|l|}{ Number of Comorbidities } \\
\hline None* & 1 & & & \\
\hline $1-3$ & 1.26 & 1.01 & 1.58 & $0.040 * *$ \\
\hline $4+$ & 1.39 & 1.08 & 1.78 & $0.011 * *$ \\
\hline \multicolumn{5}{|l|}{ Crashes } \\
\hline None* & 1 & & & \\
\hline$\geq 1$ & 1.03 & 0.82 & 1.30 & 0.811 \\
\hline \multicolumn{5}{|l|}{ Traffic Infringements } \\
\hline None* & $\mathrm{I}$ & & & \\
\hline$\geq 1$ & 0.80 & 0.67 & 0.95 & $0.011 * *$ \\
\hline \multicolumn{5}{|l|}{ Change in Driving Confidence } \\
\hline Increase/No change* & 1 & & & \\
\hline Decrease & 1.32 & 1.10 & 1.58 & $0.003 * *$ \\
\hline \multicolumn{5}{|l|}{ Preference of transport } \\
\hline Drive self* & $\mathrm{I}$ & & & \\
\hline Someone else driving & 1.38 & 1.12 & 1.70 & $0.003 * *$ \\
\hline
\end{tabular}

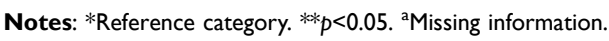
Abbreviations: $\mathrm{MCl}$, mild cognitive impairment; IRR, incidence rate ratio; $\mathrm{Cl}$, confidence interval.

one-year follow-up, compared with drivers without cognitive impairment, despite some participants reverting back to normal cognition. The earlier study by Feng et $\mathrm{al}^{27}$ also found that drivers with MCI had 39\% greater odds of selfregulating in at least one driving condition, compared with drivers without cognitive impairment and it is encouraging to see that the number of self-regulating practices for this group increased over the one-year study period.

Previous cross-sectional studies found that older drivers with MCI avoided a number of situations including driving in unfamiliar areas, and in bad weather. ${ }^{17,19,20}$
When examining specific self-regulated driving situations in our study, drivers with suspected MCI were $60 \%$ more likely to self-regulate their driving when "making turns across oncoming traffic" over the study period. A previous naturalistic study also found that older drivers experienced difficulty when making turns across oncoming traffic. ${ }^{36}$ Turning across oncoming traffic is one of the more difficult situations drivers are often faced with, requiring good gap judgement, ability to assess the speed of oncoming traffic and quick reaction time. ${ }^{37}$ These skills often diminish with age and therefore older drivers may be more likely to avoid these situations altogether. It should also be noted that while "driving on heavy traffic roads" was not significant, drivers with suspected MCI were 58\% more likely to self-regulate in this situation compared to drivers without cognitive impairment. This suggests that navigating heavy traffic may also be cognitively difficult for older drivers and is consistent with previous research. ${ }^{4}$ Further investigation with a larger sample is warranted. Although the study found that drivers with suspected MCI increased the number of situations they self-regulated in over a one-year period compared with drivers without cognitive impairment, overall there was no significant change in the number of situations the cohort selfregulated in at the second assessment. This suggests that although suspected MCI may impact driver selfregulation, the effect is minor and may not be fully due to the impact of cognition. This was also observed in a previous longitudinal driving study, which found that while older drivers increased the avoidance of more challenging driving situations over a five-year period, this increase did not occur in conjunction with decreases in functional ability, including cognition. ${ }^{21}$ Therefore, future research should investigate whether the increase in selfregulation observed in this study is enough to compensate for declines in function and cognition over a longer period of time.

There were several other health-related characteristics that significantly influenced the number of situations in which drivers self-regulated. These included advancing age, female drivers and having at least one comorbidity, which is consistent with previous research. ${ }^{15,38-40}$ Functional declines including poorer vision, ${ }^{41}$ visuospatial skills, $^{42}$ and slowed reaction times ${ }^{43,44}$ are commonly associated with the natural aging process. This is particularly pertinent for drivers aged $75+$ years, which was the age group that increased the number of driving situations in which they self-regulated their driving. A previous 
cross-sectional study found that drivers often self-regulate their driving in response to medical conditions and medication use, rather than their actual driving performance, which may explain our results. ${ }^{40}$ Previous research also found that female drivers were more likely to self-regulate in certain challenging driving situations ${ }^{45,46}$ and reduce overall driving exposure, compared to male drivers. ${ }^{47}$

In terms of attitudes towards driving, a "decrease in driver confidence" and the preference of having "someone else drive" contributed to an increase in the number of situations which drivers self-regulated their driving over the one-year study period. Previous research found that driving anxiety and lower driving confidence were associated with increased self-regulation in challenging situations and a reduction in overall driving exposure. ${ }^{39,45,48}$ It has also been previously suggested that the impact of lower driving confidence could be due to declines in functional abilities (either related to aging or health conditions) which may impact on driving. ${ }^{18}$ The majority of participants in our study had at least one comorbidity, which could have affected overall driver confidence. Furthermore, the significant interaction between gender and driving confidence is consistent with previous literature. Older female drivers self-reported being less confident in their driving skills ${ }^{46}$ particularly in certain driving situations. ${ }^{39}$ They are also more likely to cease driving and not be the principal driver of the household compared to males. $^{39,47,49}$

Another finding was that drivers who had at least one traffic infringement in the previous year experienced a decrease in the number of situations in which they selfregulated. Drivers who are not actively minimizing their crash risk by self-regulating could potentially be undertaking more risky driving behaviours. However, further research is needed on the role that driver attitudes and insight play in self-regulation practices.

The strengths of this study include the large sample size, the small attrition rate and the inclusion of sociodemographic and driving characteristics as recommended by Wong et al. The longitudinal study design also provided information related to changes in cognition, self-reported driving behaviour and self-regulation practices. However, a limitation was the classification of cognitive status using the T-CogS. Although the use of the T-CogS has been validated against the MMSE in a cohort of patients with Alzheimer's, ${ }^{29}$ it does not provide a clinical diagnosis of MCI. It was also not known whether participants who were classified with MCI were aware of their cognitive impairment. In addition, telephone interviews can provide challenges including the exclusion of those who do not own a telephone and communication issues especially for those with impaired hearing. ${ }^{50}$ Another limitation was the self-reported data which could be impacted by recall bias, social desirability bias and/or reporting bias. As participants were asked to recall their driving situations in the past three months, drivers with suspected MCI may have had difficulty in remembering events and could have led to differential misclassification. It was also noted that $17.46 \%$ of the participants reverted from suspected MCI at baseline to no cognitive impairment at the one-year follow-up. Although this reversion rate is similar to that found in another study (16\% over a one-year period), ${ }^{23}$ it is unknown whether other factors (eg, medication taken on the day, depression, inadequate sleep on day of assessment) could have contributed to their poorer T-CogS score at the first assessment. Furthermore, people who may have transitioned from suspected MCI to no cognitive impairment (or vice versa) may have only differed by one point between the two assessments, which is a limitation when using the T-CogS score to screen for suspected MCI. Nevertheless, suspected MCI was still associated with driver self-regulation practices.

\section{Conclusion}

Over a one-year period, older drivers with suspected MCI increased the number of situations in which they selfregulated their driving, compared with drivers without cognitive impairment, particularly when "making turns across oncoming traffic". This builds upon the findings from our previous study, which suggests that drivers with MCI may be able to recognize their cognitive limitations and subsequently adjust their driving accordingly. It also provides further evidence of driver self-regulation practices as an effective road safety intervention to keep older drivers with and without MCI safe as they maintain their independence through driving. Furthermore, the findings of the study emphasize the need for cognitive testing when older drivers are renewing their driving license. Lastly, future studies should examine whether this increase in the type and number of self-regulated driving situations is enough to compensate for declines in cognition.

\section{Abbreviations}

CI, confidence interval; DHQ, Driving Habits Questionnaire; GEE, generalized estimating equation; 
IRR, incidence rate ratio; MCI, mild cognitive impairment; MMSE, Mini-Mental State Examination; OR, odds ratio; $\mathrm{SD}$, standard deviation; T-CogS, Telephone Cognitive Screen; WA, Western Australia.

\section{Acknowledgments}

The authors would like to acknowledge Vicki Graham, Lyn Sargent and the Survey Research Centre, Edith Cowan University, for their assistance in recruiting and interviewing participants for this research study. The authors would also like to thank all participants for their involvement and participation in the study.

\section{Funding}

This work was supported by an Australian Research Council Linkage Grant \#LP160101446.

\section{Disclosure}

The authors report no conflict of interest in this work.

\section{References}

1. Anstey KJ, Wood J, Lord S, Walker JG. Cognitive, sensory and physical factors enabling driving safety in older adults. Clin Psychol Rev. 2005;25(1):45-65. doi:10.1016/j.cpr.2004.07.008

2. Karthaus M, Falkenstein M. Functional changes and driving performance in older drivers: assessment and interventions. Geriatrics (Basel, Switzerland). 2016;1(2):12.

3. Alonso F, Esteban C, Sanmartín J, Useche SA, Lee A. Reported prevalence of health conditions that affect drivers. Cogent Med. 2017;4(1):1303920. doi:10.1080/2331205X.2017.1303920

4. Charlton JL, Oxley J, Fildes B, Oxley P, Newstead S. Self-regulatory behaviours of older drivers. Annu Proc Assoc Adv Automot Med. 2003;47:181-194.

5. Molnar LJ, Eby DW, Charlton JL, et al. Driving avoidance by older adults: is it always self-regulation? Accid Anal Prev. 2013;57:96-104. doi:10.1016/j.aap.2013.04.010

6. Fragkiadaki S, Beratis IN, Kontaxopoulou D, et al. Self-awareness of driving ability in the healthy elderly and patients with mild cognitive impairment (MCI). Alzheimer Dis Assoc Disord. 2018;32 (2):107-113. doi:10.1097/WAD.0000000000000254

7. Petersen RC, Caracciolo B, Brayne C, Gauthier S, Jelic V, Fratiglioni L. Mild cognitive impairment: a concept in evolution. J Intern Med. 2014;275(3):214-228. doi:10.1111/joim.12190

8. Ward A, Arrighi HM, Michels S, Cedarbaum JM. Mild cognitive impairment: disparity of incidence and prevalence estimates. Alzheimers Dement. 2012;8(1):14-21. doi:10.1016/j.jalz.2011.01.002

9. Wadley VG, Okonkwo O, Crowe M, et al. Mild cognitive impairment and everyday function: an investigation of driving performance. J Geriatr Psychiatry Neurol. 2009;22(2):87-94. doi:10.1177/ 0891988708328215

10. Staplin L, Lococo K, Mastromatto T, Gish K, Golembiewski G, Sifrit K. Mild Cognitive Impairment and Driving Performance. Washington, DC: National Highway Traffic Safety Administration; 2019. (Report No DOT HS 812 577).
11. Anstey KJ, Eramudugolla R, Chopra S, Price J, Wood JM, Bondi M. Assessment of driving safety in older adults with mild cognitive impairment. J Alzheimers Dis. 2017;57(4):1197-1205. doi:10.3233/ JAD-161209

12. Frittelli C, Borghetti D, Iudice G, et al. Effects of Alzheimer's disease and mild cognitive impairment on driving ability: a controlled clinical study by simulated driving test. Int $J$ Geriatr Psychiatry. 2009;24(3):232-238. doi:10.1002/gps.2095

13. Devlin A, McGillivray J, Charlton J, Lowndes G, Etienne V. Investigating driving behaviour of older drivers with mild cognitive impairment using a portable driving simulator. Accid Anal Prev. 2012;49:300-307. doi:10.1016/j.aap.2012.02.022

14. Pavlou D, Papadimitriou E, Antoniou C, et al. Driving behaviour of drivers with mild cognitive impairment and Alzheimer's disease: a driving simulator study. TRB 2015 Annual Meeting; 2015.

15. O'Connor ML, Edwards JD, Wadley VG, Crowe M. Changes in mobility among older adults with psychometrically defined mild cognitive impairment. J Gerontol B Psychol Sci Soc Sci. 2010;65B (3):306-316. doi:10.1093/geronb/gbq003

16. Pavlou D, Papantoniou P, Papadimitriou E, et al. Self-assessment of older drivers with brain pathologies: reported habits and self-regulation of driving. $J$ Transp Health. 2017;4:90-98. doi:10.1016/j.jth.2016.08.008

17. O'Connor ML, Edwards JD, Bannon Y. Self-rated driving habits among older adults with clinically-defined mild cognitive impairment, clinically-defined dementia, and normal cognition. Accid Anal Prev. 2013;61:197-202. doi:10.1016/j.aap.2013.05.010

18. Meng A, Siren A. Cognitive problems, self-rated changes in driving skills, driving-related discomfort and self-regulation of driving in old drivers. Accid Anal Prev. 2012;49:322-329. doi:10.1016/j. aap.2012.01.023

19. Katsouri I, Athanasiadis L, Bekiaris E, Touliou K, Tsolaki M. Mild Cognitive Impairment and Driving Habits. Int $J$ Prev Med Treat. 2015;4(2A):1-10.

20. Vardaki S, Dickerson AE, Beratis I, Yannis G, Papageorgiou SG. Driving difficulties as reported by older drivers with mild cognitive impairment and without neurological impairment. Traffic Inj Prev. 2019;20:1-6.

21. Baldock M, Thompson J, Mathias J. Self-regulation of driving behaviour among older drivers: findings from a five year follow up. Australasian Road Safety Research, Policing and Education Conference, Adelaide, South Australia; 2008. Available from: https://acrs.org.au/files/arsrpe/RS080117.pdf. Accessed December 7, 2021.

22. Farias ST, Mungas D, Reed BR, Harvey D, DeCarli C. Progression of mild cognitive impairment to dementia in clinic- vs community-based cohorts. Arch Neurol. 2009;66(9):1151-1157. doi:10.1001/ archneurol.2009.106

23. Koepsell TD, Monsell SE. Reversion from mild cognitive impairment to normal or near-normal cognition: risk factors and prognosis. Neurology. 2012;79(15):1591-1598. doi:10.1212/ WNL.0b013e31826e26b7

24. Government of Western Australia. Driving tests for older drivers to be abolished; 2013. Available from: https://www.mediastatements. Wa.gov.au/Pages/Barnett/2013/11/Driving-tests-for-older-drivers-tobe-abolished.aspx. Accessed December 7, 2021.

25. Feng YR, Meuleners L. Planning for driving cessation in older drivers. Transp Res Part F Traffic Psychol Behav. 2020;72:62-70. doi:10.1016/j.trf.2020.05.005

26. Feng YR, Meuleners L, Stevenson M, et al. Driving exposure, patterns and safety critical events for older drivers with and without mild cognitive impairment: findings from a naturalistic driving study. Accid Anal Prev. 2021;151:105965. doi:10.1016/j.aap.2020.105965 
27. Feng YR, Meuleners L, Stevenson M, Heyworth J, Murray K, Maher S. Driver self-regulation practices in older drivers with and without mild cognitive impairment. Clin Interv Aging. 2020;15:217-224. doi:10.2147/CIA.S236998

28. Access Economics Pty Limited for Alzheimer's Australia WA. Projections of dementia prevalence and incidence in WA: 20102050; 2010. Available from: https://www.dementia.org.au/sites/ default/files/20100326-WA-AccessReportMar2010-Rpt-v1.pdf. Accessed December 7, 2021.

29. Newkirk LA, Kim JM, Thompson JM, Tinklenberg JR, Yesavage JA, Taylor JL. Validation of a 26-point telephone version of the mini-mental state examination. $J$ Geriatr Psychiatry Neurol. 2004;17(2):81-87. doi:10.1177/0891988704264534

30. Folstein MF, Folstein SE, McHugh PR. "Mini-mental state". A practical method for grading the cognitive state of patients for the clinician. J Psychiatr Res. 1975;12(3):189-198. doi:10.1016/ 0022-3956(75)90026-6

31. Trzepacz PT, Hochstetler H, Wang S, Walker B, Saykin AJ. Relationship between the Montreal Cognitive Assessment and Mini-mental State Examination for assessment of mild cognitive impairment in older adults. BMC Geriatr. 2015;15:107. doi:10.1186/s12877-015-0103-3

32. Petersen RC. Mild cognitive impairment as a diagnostic entity. $J \quad$ Intern Med. 2004;256(3):183-194. doi:10.1111/j.13652796.2004.01388.x

33. Owsley C, Stalvey B, Wells J, Sloane ME. Older drivers and cataract: driving habits and crash risk. J Gerontol a Biol Sci Med Sci. 1999;54 (4):M203-211. doi:10.1093/gerona/54.4.M203

34. Fraser ML, Meuleners LB, Lee AH, Ng JQ, Morlet N. Which visual measures affect change in driving difficulty after first eye cataract surgery? Accid Anal Prev. 2013;58:10-14. doi:10.1016/j. aap.2013.04.015

35. Wong IY, Smith SS, Sullivan KA, Allan AC. Toward the multilevel older person's transportation and road safety model: a new perspective on the role of demographic, functional, and psychosocial factors. J Gerontol B Psychol Sci Soc Sci. 2016;71(1):71-86. doi:10.1093/ geronb/gbu099

36. Zafian T, Ryan A, Agrawal R, Samuel S, Knodler M. Using SHRP2 NDS data to examine infrastructure and other factors contributing to older driver crashes during left turns at signalized intersections. Accid Anal Prev. 2021;156:106141. doi:10.1016/j.aap.2021.106141

37. Kloeden CN, Versteegh S, Lindsay VLA, McLean J. Right turn crashes at signalised intersections. Centre for Automotive Safety Research; 2007. Available from: http://casr.adelaide.edu.au/publica tions/researchreports/CASR007.pdf. Accessed December 7, 2021.
38. Braitman KA, Williams AF. Changes in self-regulatory driving among older drivers over time. Traffic Inj Prev. 2011;12 (6):568-575. doi:10.1080/15389588.2011.616249

39. Charlton JL, Oxley J, Fildes B, et al. Characteristics of older drivers who adopt self-regulatory driving behaviours. Transp Res Part F Traffic Psychol Behav. 2006;9(5):363-373. doi:10.1016/j. trf.2006.06.006

40. Baldock MRJ, Mathias JL, McLean J, Berndt A. Self-regulation of driving and older drivers' functional abilities. Clin Gerontologist. 2006;30(1):53-70. doi:10.1300/J018v30n01_05

41. Kline DW, Kline TJ, Fozard JL, Kosnik W, Schieber F, Sekuler R. Vision, aging, and driving: the problems of older drivers. J Gerontol. 1992;47(1):P27-34. doi:10.1093/geronj/47.1.P27

42. Jenkins L, Myerson J, Joerding JA, Hale S. Converging evidence that visuospatial cognition is more age-sensitive than verbal cognition. Psychol Aging. 2000;15(1):157-175. doi:10.1037/08827974.15.1.157

43. Doroudgar S, Chuang HM, Perry PJ, Thomas K, Bohnert K, Canedo J. Driving performance comparing older versus younger drivers. Traffic Inj Prev. 2017;18(1):41-46. doi:10.1080/ 15389588.2016.1194980

44. Svetina M. The reaction times of drivers aged 20 to 80 during a divided attention driving. Traffic Inj Prev. 2016;17(8):810-814. doi:10.1080/15389588.2016.1157590

45. Gwyther H, Holland $\mathrm{C}$. The effect of age, gender and attitudes on self-regulation in driving. Accid Anal Prev. 2012;45:19-28. doi:10.1016/j.aap.2011.11.022

46. D'Ambrosio LA, Donorfio LKM, Coughlin JF, Mohyde M, Meyer J. Gender differences in self-regulation patterns and attitudes toward driving among older adults. J Women Aging. 2008;20(3-4):265-282. doi: $10.1080 / 08952840801984758$

47. Oxley J, Charlton J. Gender differences in attitudes to and mobility impacts of driving cessation. Women's Issues Transport. 2011;2:64.

48. Blanchard RA, Myers AM. Examination of driving comfort and self-regulatory practices in older adults using in-vehicle devices to assess natural driving patterns. Accid Anal Prev. 2010;42 (4):1213-1219. doi:10.1016/j.aap.2010.01.013

49. Bauer MJ, Adler G, Kuskowski MA, Rottunda S. The influence of age and gender on the driving patterns of older adults. $J$ Women Aging. 2003;15(4):3-16. doi:10.1300/J074v15n04_02

50. Block ES, Erskine L. Interviewing by telephone: specific considerations, opportunities, and challenges. Int J Qual Methods. 2012;11 (4):428-445. doi:10.1177/160940691201100409
Clinical Interventions in Aging

\section{Publish your work in this journal}

Clinical Interventions in Aging is an international, peer-reviewed journal focusing on evidence-based reports on the value or lack thereof of treatments intended to prevent or delay the onset of maladaptive correlates of aging in human beings. This journal is indexed on PubMed Central, MedLine, CAS, Scopus and the Elsevier
Bibliographic databases. The manuscript management system is completely online and includes a very quick and fair peer-review system, which is all easy to use. Visit http://www.dovepress.com testimonials.php to read real quotes from published authors. 